\title{
FUNCTIONAL CHARACTERISTICS OF BIOACTIVE PHYTOCHEMICALS IN BETA VULGARIS L. ROOT AND THEIR APPLICATION AS ENCAPSULATED ADDITIVES IN MEAT PRODUCTS
}

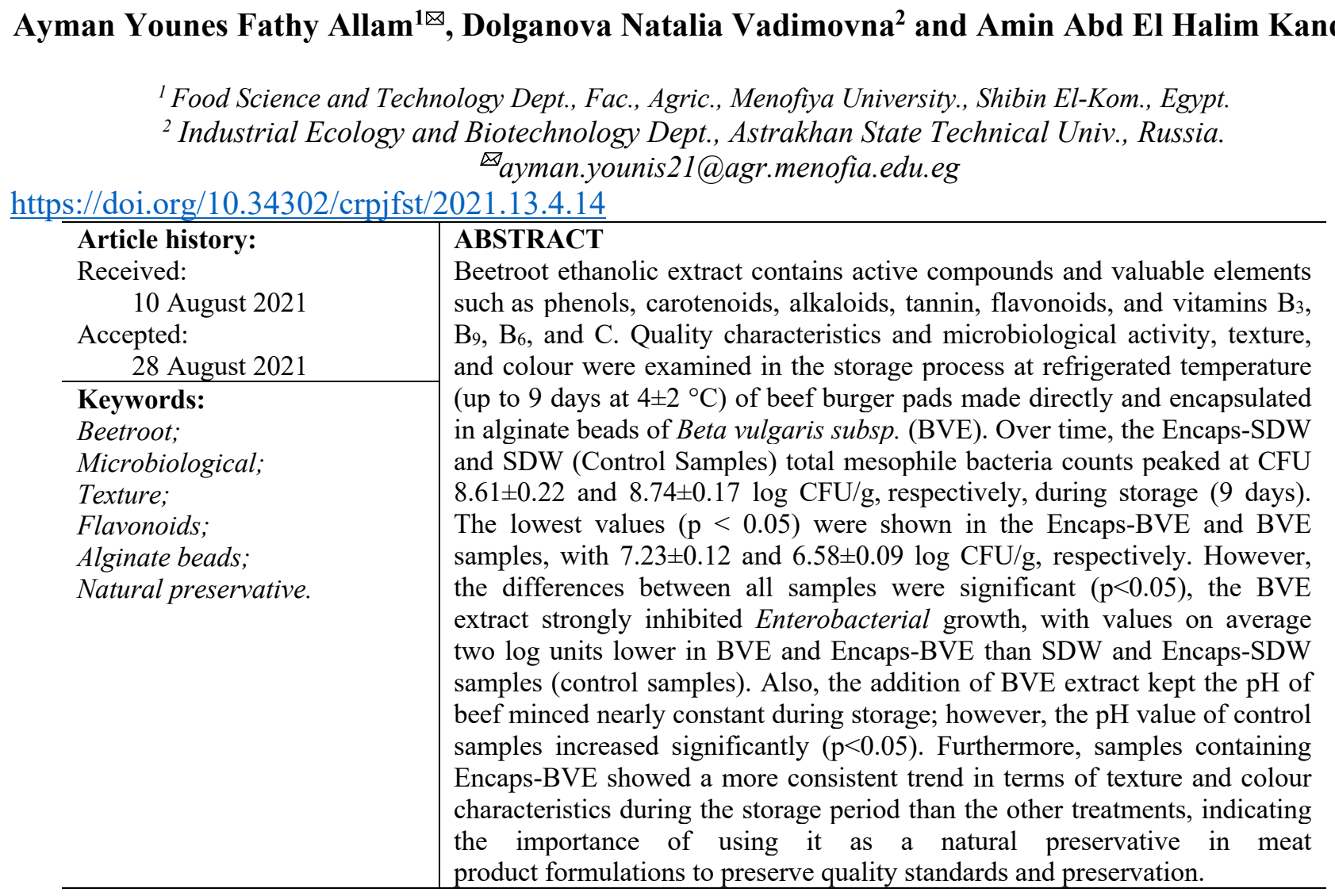

\section{Introduction}

Consumers appear to be wary of chemical additives in these cases. Thus, attention is paid to discovering natural antimicrobials occurring to preserve food due to consumer knowledge and understanding of edible food products and an increasing concern around microbial resistance to traditional preservatives (Chouhan et al., 2017). However, some conventional or regulatory licensed antimicrobials have several limitations. In these cases, customers are likely to be wary of chemical additives. Growing market demand has led to high-quality, longlife storage foods and ready-to-eat foods that are only moderately reserved and retain a natural and fresh look as much as possible
(Panchal, 2020). This has resulted in the quest for new anti-microbial compounds from natural sources. It is the potential to extract natural compounds and other natural products to contain bacteria in foods. Aromatic plants have considerable commercial value in foods, pharmaceutical industries, and cosmetics (Jain et al., 2019). Since ancient times, their use has taken place, and despite many of them being replaced by synthetic ones, demand for natural products is increasing. As an antimicrobial agent for food preservation, numerous extracts have emerged on the market in recent years. Scaling up antimicrobials' activity across the permitted regulatory substances is the primary 
incentive to identify effective antimicrobials among natural compounds. Medicinal plant extracts are now emerging as alternatives to traditional natural preservatives to control the growth of foodborne pathogens and food spoilage bacteria, as they are generally healthy for humans and environmentally friendly. Microbe contamination, which impairs food quality and results in financial losses, is one of the most severe issues in the food sector processing. (Priyadarshani \& Rath, 2012; Aneja et al., 2014; Flores \& Toldrá, 2020; Fortunati et al., 2019; Ni et al., 2021).

Beta vulgaris L. subsp. vulgaris is a Chenopodiaceae (Angiosperm) family member and is commonly referred to as beets or garden beetroot. Beetroot varies in colour from yellow to purple red depending on the variety. Red beets are consumed by humans worldwide. Beetroot is a biannual herbaceous agricultural plant that is farmed for its edible roots and leaves. Salads, soups, jams, and juice are made with beetroots (Goldman \& Navazio, 2003). Moreover, because the leaves are high in vitamins and antioxidants, they can be consumed raw or cooked as a spinach alternative. Due to betalains pigments in red beets, they have pharmaceutical and commercial applications, including food product coloring, medicinal formulations, cosmetics, and artwork (Neelwarne \& Halagur, 2013; De-Ancos et al., 2015; Celli \& Brooks, 2017; Kumar \& Brooks, 2018; Miguel, 2018;). As a result, using effective antimicrobial agents found in fruits and vegetables to guard against microorganisms (bacteria and fungi) is a crucial strategy to solving this problem. Antibacterial, anti-inflammatory, antioxidant, antithrombotic, antiatherogenic, cardioprotective, antiallergenic, and vasodilatory effects have been found in red beets (Gliszczynska \& Anna, 2013; De-Ancos et al., 2015).

One of the main aspects in enhancing study the chemical composition of red beetroots quality, prolonging shelf-life, maintaining consumer protection, product safety, and minimizing waste was the microbial control in minced beef. The primary purpose of this investigation was to improve the overall stability and quality of beef meat by using two different techniques to incorporate Beta Vulgaris L. root: direct processing and encapsulation in sodium alginate and encapsulation in sodium alginate. During refrigerated storage at $4 \pm 2{ }^{\circ} \mathrm{C}$, the microbial characteristics, texture, colour, and $\mathrm{pH}$ of beef patties were investigated.

\section{Materials and methods}

\subsection{Extraction Technique}

The roots of Beta vulgaris subsp. Vulgaris var. Plano (sugar beet-red beetroot) was collected from the local market in Egypt and transported to the meat products laboratory in the Food Sci. and Tech. Dept., Faculty of Agri., Menoufia Univ. within 1-2 hours at room temperature into plastic boxes. The roots were manually peeled after being rinsed and cleansed with tap water, and then the roots were freeze-dried and ground into a soft powder (a crude extract) using an electric blender. The crud extract was dried in an oven at $35-40{ }^{\circ} \mathrm{C}$ for $24-30 \mathrm{hr}$. The crud extract $(500$ $\mathrm{mg}$ ) was separated for 24 hours using a shaker in $100 \mathrm{ml}$ ethanol or distilled water, and then the solution was filtered and refrigerated at 4 ${ }^{\circ} \mathrm{C}$ until use.

\subsubsection{Total Polyphenol}

The Folin-Ciocalteu reagent assay was estimated to stain the extract's total phenolic content (Ozsoy et al., 2008). 0.4g dry sample obtained with $20 \mathrm{ml}$ ethanol $80 \%$, soaked in brawn bottle for 24 hours at room temperature, centrifuged for 5 minutes, volume adapted to $25 \mathrm{ml}$ by ethanol $80 \%$, filtered via Whatman no.1 filter paper, $10 \mathrm{ml}$ of the solution evaporated to dryness, dissolved in $5 \mathrm{ml}$ HPLC grade methanol $50 \%$, filtered through PTFE filter with pore size $0.2 \mu \mathrm{m}$. Subsequently, the mixture was incubated for 30 minutes at room temperature $\left(22{ }^{\circ} \mathrm{C} \pm 2\right)$, and the absorbance was measured with a spectrophotometer at 760 nm (School instrument, UV line 9400, EU). For the calibration curve, gallic acid was used as a standard material. Total phenolic content expressed as gallic acid equivalent. Both experiments were carried out in triplicate. 


\subsubsection{Total Flavonoids}

The total flavonoids content was measured using the (Sakanaka et al., 2005) process. A 0.5 $\mathrm{ml}$ of extract was placed in a $10 \mathrm{ml}$ volumetric flask. Distilled water was added to make an even volume of $5 \mathrm{ml}$, followed by $0.3 \mathrm{ml}$ $\mathrm{NaNO}_{2}$ (1:20). 5 min later, $3 \mathrm{ml} \mathrm{AlCl} 3(1: 10)$ were added. After $6 \mathrm{~min}, 2 \mathrm{ml}$ of $\mathrm{NaOH}(4 \%)$ were added, and then by using distilled water, the total volume increased to $10 \mathrm{ml}$. The solution was mixed well again, and the absorbance was measured against a blank at $510 \mathrm{~nm}$ using a spectrophotometer (Schoot instrument, UV line 9400, EU). The findings were expressed as $\mathrm{mg}$ of sample quercetin $/ \mathrm{g}$. All measurements were collected in triplicate.

Condition of the instrument measuring total phenolic and flavonoid compounds: Agilent 1260 infinite HPLC Series (Agilent, USA) with Quaternary pump and a Kinetex XB-C18 (Phenomenex, USA) column $100 \mathrm{~mm}$ $\mathrm{x} 4.6 \mathrm{~mm}$ running at $35{ }^{\circ} \mathrm{C}$. The separation is achieved using a ternary linear elution gradient with (A) HPLC grade water $0.2 \% \mathrm{H}_{3} \mathrm{PO}_{4}(\mathrm{v} / \mathrm{v})$, (B) methanol, and (C) acetonitrile. The total volume injected was $20 \mu \mathrm{L}$. VWD detector calibrated at $284 \mathrm{~nm}$ for detection. The total volume injected was $20 \mu \mathrm{L}$ to measuring total flavonoids compounds. UV detector tuned at $273 \mathrm{~nm}$ for detection and database management using claritychrom@ software. This methodology was modified from Mattila et al. (1989) and Goupy et al. (1999). For fractionating flavonoids and polyphenols.

\subsubsection{Water-soluble vitamins (WSV)}

The WSV was evaluated by HPLC analysis following sample extraction as suggested by Albalá-Hurtado et al. (1997). A sample of dried beets $(0.2 \mathrm{~g})$ was weighed to a centrifuge tube together with $15 \mathrm{~mL}$ deionized water. Centrifuge at $4000 \mathrm{rpm}$ for 5 minutes after 15 minutes of extraction, then transfer quantitatively to a $25 \mathrm{~mL}$ volumetric flask adding more water to the mark: before treatment, filter over a $0.2 \mu \mathrm{m}$ nylon membrane.

Condition of the instrument measuring Water-soluble vitamins: Agilent 1260 infinite HPLC Series (Agilent, USA) with Quaternary pump and a Kinetex XB-C18 (Phenomenex,
USA) column $100 \mathrm{~mm} \times 4.6 \mathrm{~mm}$ running at 35 ${ }^{\circ} \mathrm{C}$. A double linear elution gradient using (A) $25 \mathrm{mM} \mathrm{NaH}_{2} \mathrm{PO}_{4}$ at $\mathrm{pH}=2.5$ and (B) methanol is used to separate the samples. The total volume injected was $20 \mu \mathrm{L}$. Ascorbic acids are detected at $254 \mathrm{~nm}$, while vitamins B6, B3, B9, and B12 are detected at $220 \mathrm{~nm}$ (Mattila et al., 1989).

\subsubsection{Total Tannin}

Folin-Denis's reagent is used to determine the tannin concentration in red beetroots, as suggested by (Saxena et al., 2016). A spectrophotometer (Schoot instrument, UV line 9400, EU) was used to determine the absorbance at $700 \mathrm{~nm}$.

\subsubsection{Total Alkaloid}

The alkaloids were determined using Adham's technique (Adham et al., 1998). The $\%$ alkaloid was defined as follows:

$$
\% \text { Total Alkaloid }=\frac{\text { Weight of remain }}{\text { Weight of Sample }} \times 100
$$

\subsubsection{Total Anthocyanins}

In methanol containing $1 \% \mathrm{HCl}(\mathrm{v} / \mathrm{v})$, fresh beetroot was homogenized and then filtrated. A spectrophotometer (Schoot instrument, UV line 9400, EU) was used to read the filtration at 530 and $657 \mathrm{~nm}$, as Mancinelli et al. (2006) suggested.

\subsubsection{Total carotenoid}

Total carotenoids of beetroot were obtained using a mixture of acetone: hexane $(1: 1 \mathrm{v} / \mathrm{v})$, as Jeyanthi et al. (2014) presented. And to use a spectrophotometer (Schoot instrument, UV line $9400, \mathrm{EU})$, the absorbance of carotenoids was determined at $630 \mathrm{~nm}$.

\subsection{Preparation of roots of Beta vulgaris in Berger:}

Red-colored extract (dry crud extract) was diluted in an equivalent volume of (1:3) sterile distilled water (SDW) was used to add directly or encapsulated to minced beef.

\subsubsection{Encapsulation of BVE}

Encapsulation of Beta vulgaris subsp. extract (BVE) in sodium alginate was administered as designed by (Ribeiro \& Veloso, 2020). In summary, according to the 
method described above, a defined volume with diluted BVE was blended with sodium alginate $0.5 \%(\mathrm{w} / \mathrm{v})$ and allowed the solution to dissolve homogeneously. Once the BVEalginate solution was homogeneous, the weight was recorded, and the solution was injected into a calcium chloride solution of $1.5 \%(\mathrm{w} / \mathrm{v})$ using a syringe $(0.80 \mathrm{~mm} \times 25 \mathrm{~mm})$. The beads were cleaned and filtered using sterile Whatman ${ }^{\circledR}$ class I paper, then allowed to settle for 20 minutes in the air before being weighed to ensure any BVE during the pelleting process, and there is a loss. According to (Aguirre \& Santagapita, 2016), the projected pill size, which might include SDW or BVE, was estimated by scanning digital images of beads (taken with a brother MFC-7360N scanner) the free license program ImageJ1. The standard deviation is an expression of the size of the beads with an average diameter of the ferret that agrees with the total distance $(\mathrm{mm})$ between any two or more point's places and the bead limits.

\subsubsection{Beef Burger Patty Preparation}

Beef mince from two different batches $(3 \mathrm{~kg} \mathrm{x}$ $2 \mathrm{~kg}$ ) was purchased at a local market in Shebin El-Kom (Egypt), brought to the meat products lab in a transportable refrigerator at $4 \pm 2{ }^{\circ} \mathrm{C}$ (within 30min), and rapidly utilized for further meat combinations. To achieve a homogeneous mixture, each lot $(1 \mathrm{~kg})$ of minced beef was mixed in a bowl with $0.8 \%(\mathrm{w} / \mathrm{w})$ of $\mathrm{NaCl}$ for 3 minutes, which had been categorized into four $250 \mathrm{~g}$ experimental groups; each module was added with sterile distilled water (SDW $5 \%, \mathrm{v} / \mathrm{w})$, encapsulated sterile distilled water (Encaps-SDW 5\%, v/w), Beta vulgaris subsp. extract (BVE 5\%, v/w), encapsulated Beta vulgaris subsp. extract (Encaps-BVE 5\%, v/w). The $5 \%(\mathrm{v} / \mathrm{w})$ concentration of Beta vulgaris subsp. the extract was chosen based on previous research on beef slices (Aminzare et al., 2015); Parafiti et al., 2018). Several concentrations of Beta vulgaris extract were tested to see which one type of most inhibited microbial growth while refrigerated storage. Burger samples were made with a burger patty builder to achieve a comparable weight and size (about $50 \mathrm{~g}$, with a diameter ranging of 5 $\mathrm{cm}$ and a thickness of $2 \mathrm{~cm}$ ) and labeled as shown in Table 1. All samples were mobilized in an aerobic environment on a food tray with a sealed plastic polyethylene membrane and kept at $4 \pm 2{ }^{\circ} \mathrm{C}$ in a refrigerator. Prepared burger samples were used to add SDW, each encapsulated with or without sodium alginate, to ground beef as controls. Each sample from every batch was investigated for $\mathrm{pH}$ values, microbial parameters, colour characteristics (CIE $a^{*}, L^{*}$, and $b^{*}$ ), and profile of texture properties after $0,3,6$, and 9 days of storage period at $4 \pm 2{ }^{\circ} \mathrm{C}$.

Table 1. The study's beef burger formulation.

\begin{tabular}{|l|l|}
\hline Treatment & \multicolumn{2}{|l|}{ Ingredients in burger patties } \\
\hline SDW & $\begin{array}{l}\text { Minced meat }+0.8 \% \quad(\mathrm{w} / \mathrm{w}) \\
\mathrm{NaCl} 5 \% \quad(\mathrm{v} / \mathrm{w}) \quad \text { sterile } \\
\text { distilled water }\end{array}$ \\
\hline $\begin{array}{l}\text { Encaps- } \\
\text { SDW }\end{array}$ & $\begin{array}{l}\text { Minced meat }+0.8 \% \quad(\mathrm{w} / \mathrm{w}) \\
\mathrm{NaCl}+5 \% \quad(\mathrm{v} / \mathrm{w}) \text { of } \\
\text { distilled waterile } \\
\text { alginate beads }\end{array}$ \\
\hline BVE & $\begin{array}{l}\text { Minced meat }+0.8 \% \quad(\mathrm{w} / \mathrm{w}) \\
\mathrm{NaCl}+5 \% \quad(\mathrm{v} / \mathrm{w}) \\
\text { encapsulated Beta } \\
\text { subsp. extract }\end{array}$ \\
\hline $\begin{array}{l}\text { Encaps- } \\
\text { BVE }\end{array}$ & $\begin{array}{l}\text { Minced meat }+0.8 \% \quad(\mathrm{w} / \mathrm{w}) \\
\text { NaCl }+5 \%(\mathrm{v} / \mathrm{w}) \text { Beta vulgaris } \\
\text { subsp. extract encapsulated in } \\
\text { alginate beads }\end{array}$ \\
\hline
\end{tabular}

\subsection{Microbiological Analysis}

The antibacterial activity of potential microbial evaluation of the Beta vulgaris subsp. extract (BVE) added to the preparation of pies burgers, both coated and non-coated in sodium alginate granules, was predestined by observing the increase of the microbial population after 0 , 3 , 6, and 9 days of storage at $4 \pm 2{ }^{\circ} \mathrm{C}$. In summary, a part of every sample $(10 \mathrm{~g})$ was aseptically placed in a stomacher filter package containing $90 \mathrm{ml}$ of sterile Ringer's solution, homogenized for 5 minutes, then serially diluted afterward. To observe the growth of total Pseudomonas, total mesophilic bacteria, and Enterobacteriaceae, suitable dilutions were plated in Petri dishes plate Count Agar with 
Violet Red Bile Glucose Agar, cycloheximide $0.1 \%$ solution, and Pseudomonas Agar Base, supplemented with Pseudomonas CFC selective agar supplement (SR-0103). At 35 or $25{ }^{\circ} \mathrm{C}$, the dishes were incubated for $24-48$ hours (Pseudomonas spp. count). Microorganisms were calculated using three replicates, with the mean represented as log $\mathrm{CFU} / \mathrm{g}$ of burger \pm standard deviation.

\section{4. pH Values}

The $\mathrm{pH}$ values of samples were measured by using a digital $\mathrm{pH}$ meter (Model 3510, Jenway Technology, Italy). With the help of two buffer solutions of $\mathrm{pH} 4$ and 7, the $\mathrm{pH}$ meter electrode was calibrated. In a CycloMixer, $15 \mathrm{~g}$ of finely powdered sample was mixed in $50 \mathrm{ml}$ of distilled water in a test tube (CM- Model 3000 USA). It was obtained using Whitman filter paper No. 1 as a filter. The $\mathrm{pH}$ meter's electrode was immersed in the filtrate, and the sample $\mathrm{pH}$ was measured. All values were calculated as the average of three replicates \pm standard deviation (Khandil et al., 2020).

\subsection{Instrumental colour}

The beef samples patty was pressed on a flat surface. The Hunter $\left(a^{*}, b^{*}\right.$, and $\left.L^{*}\right)$ scale colour difference was determined using a scale colour spectrophotometer (machine colors Tristimulus) and a CIE Lab colorimeter (Hunter, Lab Scan XE - Reston, VA, USA) in reflection mode, with the colorimeters held over the samples at room temperature at $25^{\circ} \mathrm{C}$ (Tatli et al., 2020; Muge et al., 2020).

\subsection{Instrumental texture}

The texture characteristics of the burger samples were determined using Mercadante et al. (2010) methodologies with slight modifications. The burger samples were first taken from the casings and sliced into $2.5 \mathrm{~cm}$ length pieces before being compressed twice with a Texture Analyzer (Texture Analyzer TA-HD plus, $750 \mathrm{~kg}$. (7.5 kN), England).
Textural characteristics were evaluated at room temperature with the following processing parameters: $5.0 \mathrm{~mm} / \mathrm{s}$ crosshead speed, $99.0 \mathrm{~g}$ surface sensing force, and $30.0 \mathrm{~g}$ threshold using a diameter cylindrical aluminum probe $(5 \mathrm{~cm} \times 4 \mathrm{~cm}) 1 s$ time gap between the first and second compressions. The Texture Professional version 1.0 program collected and analyzed the data (Stable Micro Systems, Surrey, England). The force-time curves were used to determine each sample's hardness, gumminess, springiness, cohesiveness, and chewiness (Bourne, 1978; Muge et al., 2020). The results were based on the average and standard deviation $( \pm)$ of three replicates with one burger for each measurement.

\subsection{Statistical Analysis}

All experimental data were represented as mean values with \pm standard deviation. Data from various tests were examined separately and compared using a one-way analysis of variance (ANOVA). Based on (Artimage \& Berry, 1987; Kowalczewski \& Andreani, 2015) (Laleg et al., 2019) protocols with minor adjustments, the significance of differences between the means was compared using Fisher's test $(p<0.05)$. The data is displayed as mean SD $(+)$. According to Fisher's least significant difference test $(p<0.05)$, results followed by different letters within the same storage duration $(0,3,6$, and 9 days $)$ are significantly different in each row.

\section{Results and discussions}

\subsection{Red beet root's chemical components.}

Which is shown in Table 2, total phenolics $(130.44 \pm 0.11 \mathrm{mg} / \mathrm{g} \mathrm{DW})$, total flavonoids $(1.22 \pm 0.251 \mathrm{mg} / \mathrm{g} \quad \mathrm{DW})$, total tannin $(4.89 \pm 0.114 \mathrm{mg} / \mathrm{g} \mathrm{DW})$, total anthocyanins $(59.89 \pm 0.082 \mathrm{~g} / 100 \mathrm{~g}$ FW), total alkaloid (2.54 $\pm 0.018 \mathrm{~g} / 100 \mathrm{~g} \quad \mathrm{DW})$, and carotenoids $(1.55 \pm 0.221 \mathrm{mg} / 100 \mathrm{~g} \mathrm{FW})$ are present in the ethanolic extract. 
Table 2. The Quantitative chemical composition, Phenolic and Flavonoid compounds, and Watersoluble Vitamins of Beta vulgaris root

\begin{tabular}{|l|c|}
\hline \multicolumn{1}{|c|}{ Components } & Composition \\
\hline Total phenolic (mg Gallic acid /g DW) & $130.44 \pm 0.11$ \\
\hline Total flavonoid (mg Quercetin /g DW) & $1.22 \pm 0.251$ \\
\hline Total tannin (mg Tannic acid /g DW) & $4.89 \pm 0.114$ \\
\hline Total alkaloid (g/100g DW) & $2.54 \pm 0.018$ \\
\hline Total anthocyanin $(\mu \mathrm{g} / 100 \mathrm{~g}$ FW) & $59.89 \pm 0.082$ \\
\hline Carotenoids (mg/100g FW) & $1.55 \pm 0.221$ \\
\hline Phenolic compounds (Conc. mg/100g DW) & $10.22 \pm 0.02$ \\
\hline Gallic acid & $6.88 \pm 0.11$ \\
\hline Catechol & $0.58 \pm 0.14$ \\
\hline p-Comuaric acid & $0.88 \pm 0.08$ \\
\hline Ferulic acid & $1.47 \pm 0.24$ \\
\hline o-Coumaric acid & $0.74 \pm 0.43$ \\
\hline Cinnamic acid & \\
\hline Flavonoid compounds (Conc. mg/100g DW) & $20.22 \pm 0.11$ \\
\hline Myricetin & $19.42 \pm 0.24$ \\
\hline Naringenin & $2.98 \pm 0.47$ \\
\hline Kaempferol & $2.78 \pm 0.42$ \\
\hline Apigenin & \\
\hline Vitamins contents (Water-soluble Vit.: mg/100g DW) \\
\hline Ascorbic acid (Vit. C) & $25.87 \pm 0.17$ \\
\hline Niacin (Vit. B3) & $1.47 \pm 0.10$ \\
\hline Pyridoxine (Vit. B6) & $5.879 \pm 0.08$ \\
\hline Folic acid (Vit. B9) & $2.59 \pm 0.31$ \\
\hline Note: Values are mean \pm SD of three replicate analyses \\
\hline \multicolumn{2}{|l|}{ (10) } \\
\hline
\end{tabular}

Soluble vitamins are identified using HPLC. The ethanolic extract of red beetroot includes vitamin $\mathrm{C}(25.87 \pm 0.17 \mathrm{mg} / 100 \mathrm{~g} \mathrm{DW})$, vitamin B3 (1.47 $\pm 0.10 \mathrm{mg} / 100 \mathrm{~g} \mathrm{DW})$, vitamin B6 (5.879 $\pm 0.08 \mathrm{mg} / 100 \mathrm{~g} \mathrm{DW})$, and vitamin B9 (2.60 $\mathrm{mg} / 100 \mathrm{~g} \mathrm{DW}$, according to the data in Table 1. Phenolic compounds are separated by using HPLC). Table 1 shows that catechol $(6.88 \pm 0.11 \mathrm{mg} / 100 \mathrm{~g} \quad \mathrm{DW})$, ferulic acid $(0.88 \pm 0.08 \mathrm{mg} / 100 \mathrm{~g} \quad \mathrm{DW})$, gallic acid $(10.22 \pm 0.02 \mathrm{mg} / 100 \mathrm{~g} \mathrm{DW}), p$-Comuaric acid $(0.58 \pm 0.14 \mathrm{mg} / 100 \mathrm{~g})$, and o-Cinnamic acid $(0.74 \pm 0.43 \mathrm{mg} / 100 \mathrm{~g})$ are all present in the ethanolic extract of red beetroot. Furthermore, the ethanolic extract of red beetroot includes a variety of flavonoids, including naringenin $(19.42 \pm 0.24 \mathrm{mg} / 100 \mathrm{~g} \quad \mathrm{DW}), \quad$ myricetin $(20.22 \pm 0.11 \mathrm{mg} / 100 \mathrm{~g} \quad \mathrm{DW}), \quad$ apigenin
$(2.78 \pm 0.42 \mathrm{mg} / 100 \mathrm{~g} \mathrm{DW})$, and kaempferol $(2.98 \pm 0.47 \mathrm{mg} / 100 \mathrm{~g} \mathrm{DW})$.

\section{2. $\mathrm{pH}$ Determination}

The $\mathrm{pH}$ values are presented in Fig. 1 correspond to burger patties containing BVE, either encapsulated or/not encapsulated in sodium alginate, and to Encaps-SDW or SDW samples control stored at $4 \pm 2^{\circ} \mathrm{C}$ for 9 days. The samples Encaps-SDW, SDW, BVE, and Encaps-BVE, had comparable beginning $\mathrm{pH}$ values of $5.97 \pm 0.13,5.94 \pm 0.11,6.03 \pm 0.11$, and $5.98 \pm 0.14$ for Encaps-SDW, SDW, BVE, and Encaps-BVE extract, respectively, right after treatment (0 times). As compared to the SDW (control samples), the BVE sample had a significantly $(\mathrm{p}<0.05)$ higher $\mathrm{pH}$ value of $6.03 \pm 0.11$. While the $\mathrm{pH}$ of the Encaps-SDW and SDW control samples remained stable (approximately at 5.96) after three days of 
storage, the $\mathrm{pH}$ of the Encaps-BVE and BVE samples significantly decreased $(p<0.05)$, reaching $5.31 \pm 0.15$ and $5.49 \pm 0.11$, respectively. The $\mathrm{pH}$ value in the SDW sample increased significantly $(p<0.05)$ after six days of storage (Figure1), reaching $6.61 \pm 0.15$. This was nearly constant $(6.03 \pm 0.12)$ in Encaps- SDW, whereas sample BVE had the lowest values of $5.17 \pm 0.09$, substantially $(\mathrm{p}<0.05)$, confirmed by Encaps$\mathrm{BVE}$ at $5.13 \pm 0.05$. After 9 days of storage, the variation in $\mathrm{pH}$ values was significantly greater. Indeed, the $\mathrm{pH}$ of BVE and Encaps-BVE samples was $5.16 \pm 0.12$ and $5.54 \pm 0.10$, respectively. In contrast, the $\mathrm{pH}$ of SDW and Encaps-SDW samples was significantly higher at $7.11 \pm 0.14$ and $6.89 \pm 0.05$, respectively.

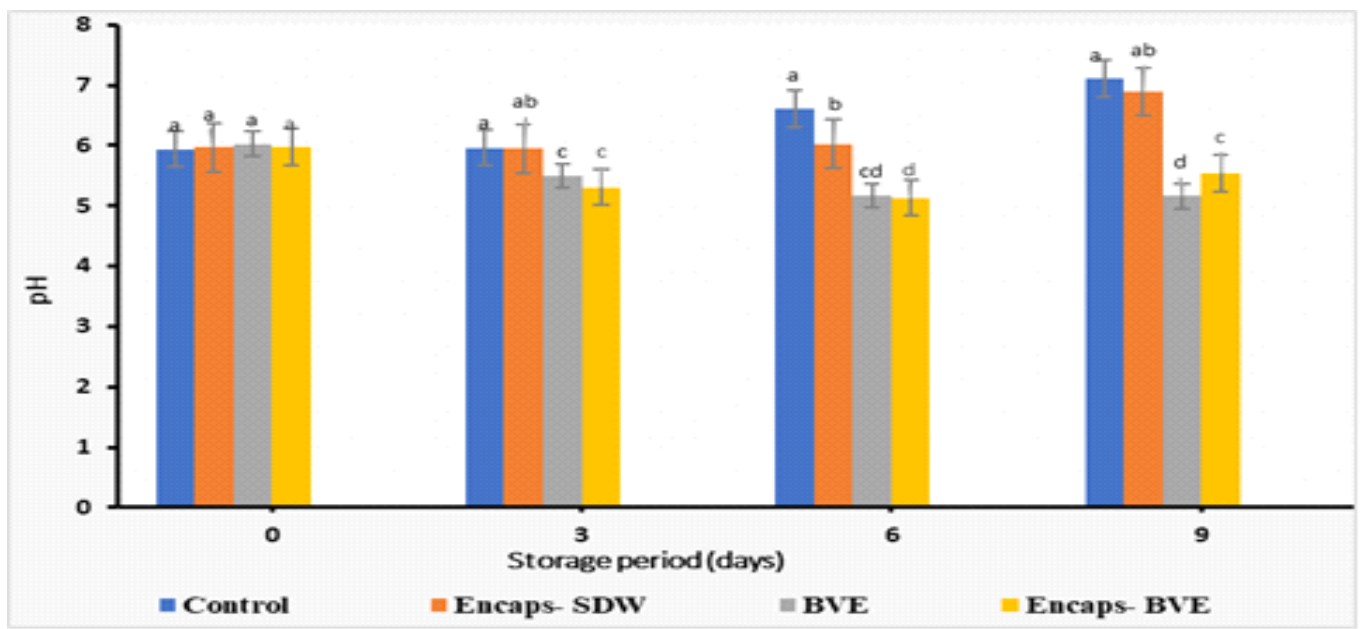

Figure 1. $\mathrm{pH}$ values of beef burger patties incorporating Beta vulgaris root extract (BVE) or sterile distilled water (SDW) during 9 days of storage at $4 \pm 2{ }^{\circ} \mathrm{C}$.

\subsection{Microbiological Analysis}

Figures 2, 3 and 4 show the microbiological counts on burger patties with or without Beta vulgaris extract, each encapsulated or/not encapsulated in sodium alginate, after 9-days of storage $\left(4 \pm 2{ }^{\circ} \mathrm{C}\right)$. In furthermore, vitamins $\mathrm{A}$, $\mathrm{B}$, and $\mathrm{C}$, as well as folic acid, can help with motor function. On plate count agar, the initial estimate of Total Mesophilic Bacteria has been $4.8 \log \mathrm{CFU} / \mathrm{g}$ throughout all treatment (BVE and SDW). Despite this, it immediately rose after three days of storage, exceeding the European regulation's limit of 7.14 to $7.32 \mathrm{log}$ $\mathrm{CFU} / \mathrm{g}\left(5 \times 10^{6} \mathrm{CFU} / \mathrm{g}\right)$ for total aerobic bacterial counts (Regulation EC-2073, 2005). Although Total Mesophilic Bacteria count increased during six days of storage in EncapsSDW and control samples SDW, it stayed relatively constant in Encaps- BVE and BVE samples. Total Mesophilic Bacteria count achieved peak values of $8.61 \pm 0.22$ and $8.74 \pm 0.17 \mathrm{log} \mathrm{CFU} / \mathrm{g}$ in Encaps-SDW and
SDW (control samples), respectively, at the end of storage ( 9 days). Encaps-BVE and BVE samples, on the other hand, had the lowest values $(\mathrm{p}<0.05)$ at $7.23 \pm 0.12$ and $6.58 \pm 0.09 \log$ $\mathrm{CFU} / \mathrm{g}$, respectively, even though the EncapsBVE was inside the microbiological limit (Fig. 2). The count of Enterobacteriaceae on burger patties processed with Encaps-SDW, EncapsBVE, and BVE samples (Fig. 3), were not statistically different $(p>0.05)$ from the SDW sample $(5.41 \pm 0.13 \mathrm{log}$ CFU $/ \mathrm{g})$ initially after procedures (0 days). The BVE and EncapsBVE samples had the lowest enterobacteria counts $(p<0.05)$ after 3,6 , and 9 days of storage when evaluated to Encaps-SDW and control samples SDW. Although there were some differences between samples, the BVE strongly inhibited enterobacterial growth, with values averaged $2 \log$ units lesser in measurements of Encaps-BVE and BVE (6.45 \pm 0.15 and $6.01 \pm 0.09 \log \mathrm{CFU} / \mathrm{g}$, respectively) than SDW 
and Encaps-SDW samples at the end of storage (9 days).

Figure 4, Pseudomonas spp. counts began at $4.12 \pm 0.11 \log \mathrm{CFU} / \mathrm{g}$ and grew in all tests performed after 9-days of storage, although significant differences probably depend on treatments and experimental conditions. During 6 and 9 days, all samples containing BVE had considerably lower values $(p<0.05)$ than SDW and Encaps-SDW, which had the highest values of $8.77 \pm 0.13$ and $8.12 \pm 0.11 \log \mathrm{CFU} / \mathrm{g}$, respectively. Immediate addition of $\mathrm{BVE}$ $(6.44 \pm 0.16 \log \mathrm{CFU} / \mathrm{g})$ produced the most significant review $(p<0.05)$ at the end of storage (9 days), followed by encapsulated SDW (8.12 $\pm 0.05 \log \mathrm{CFU} / \mathrm{g})$ and encapsulated BVE (7.55 $\pm 0.09 \log \mathrm{CFU} / \mathrm{g})$.

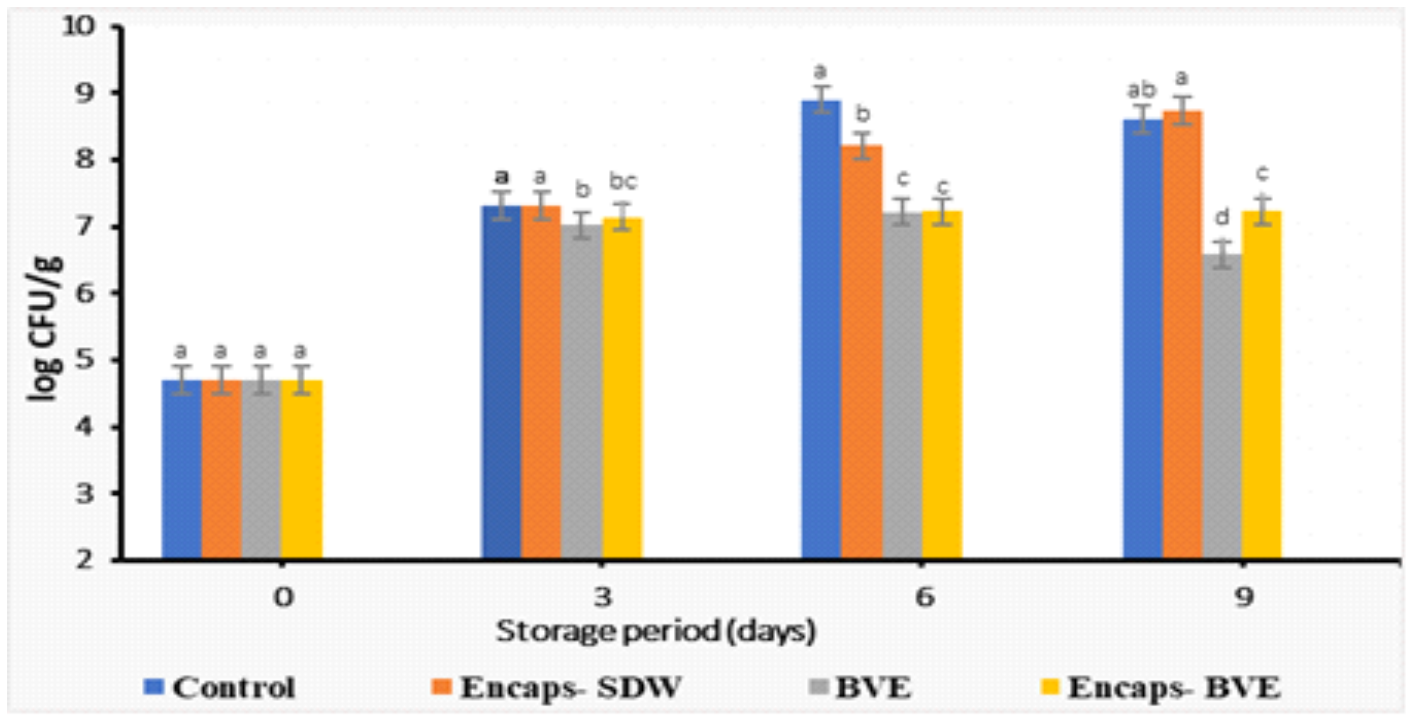

Figure 2. Total mesophilic bacteria (TMB) of beef burger patties incorporating Beta vulgaris L. root extract (BVE) or sterile distilled water (SDW) during 9 days of storage at $4 \pm 2{ }^{\circ} \mathrm{C}$.

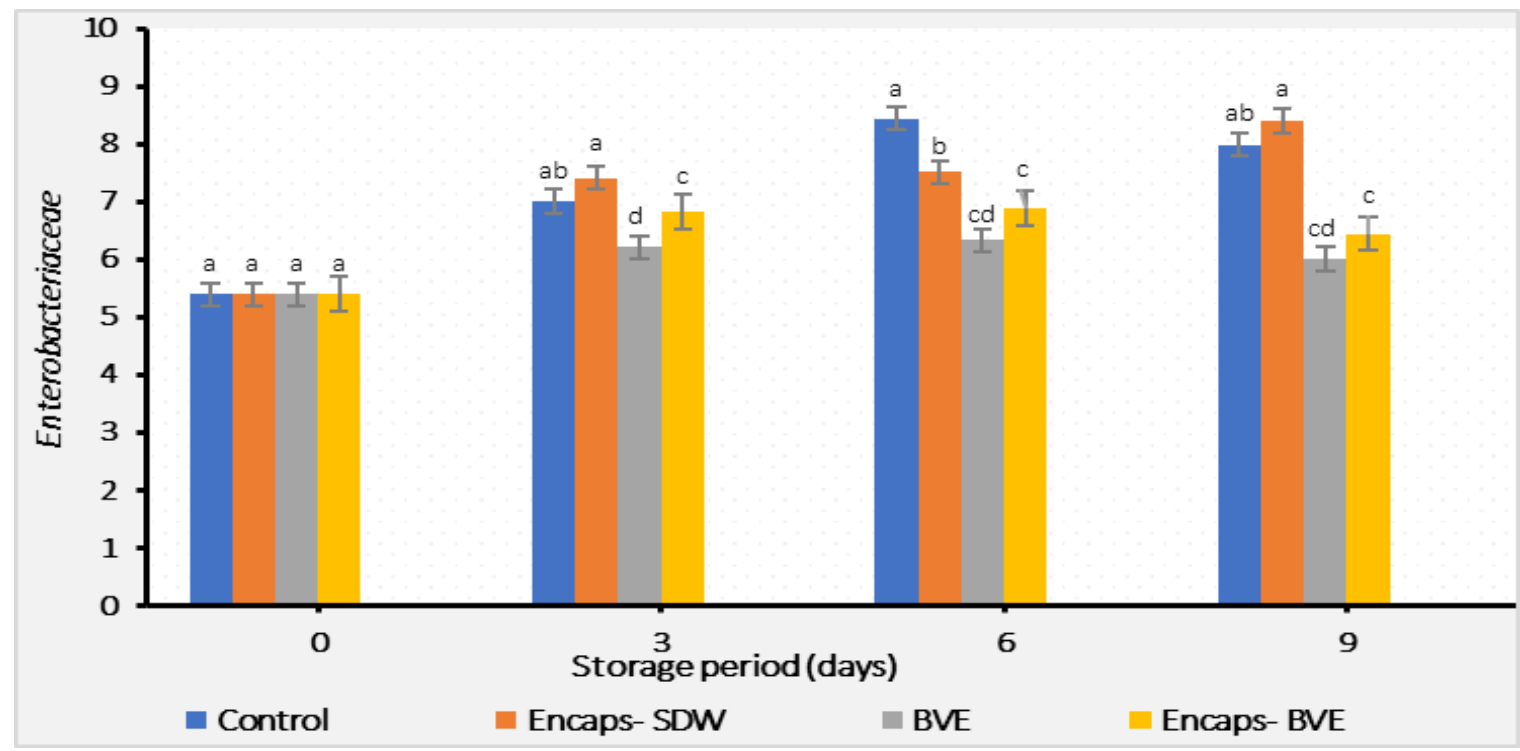

Figure 3. Growth of Enterobacteriaceae of beef burger patties incorporating Beta vulgaris L. root extract (BVE) or sterile distilled water (SDW) during 9 days of storage at $4 \pm 2{ }^{\circ} \mathrm{C}$. 


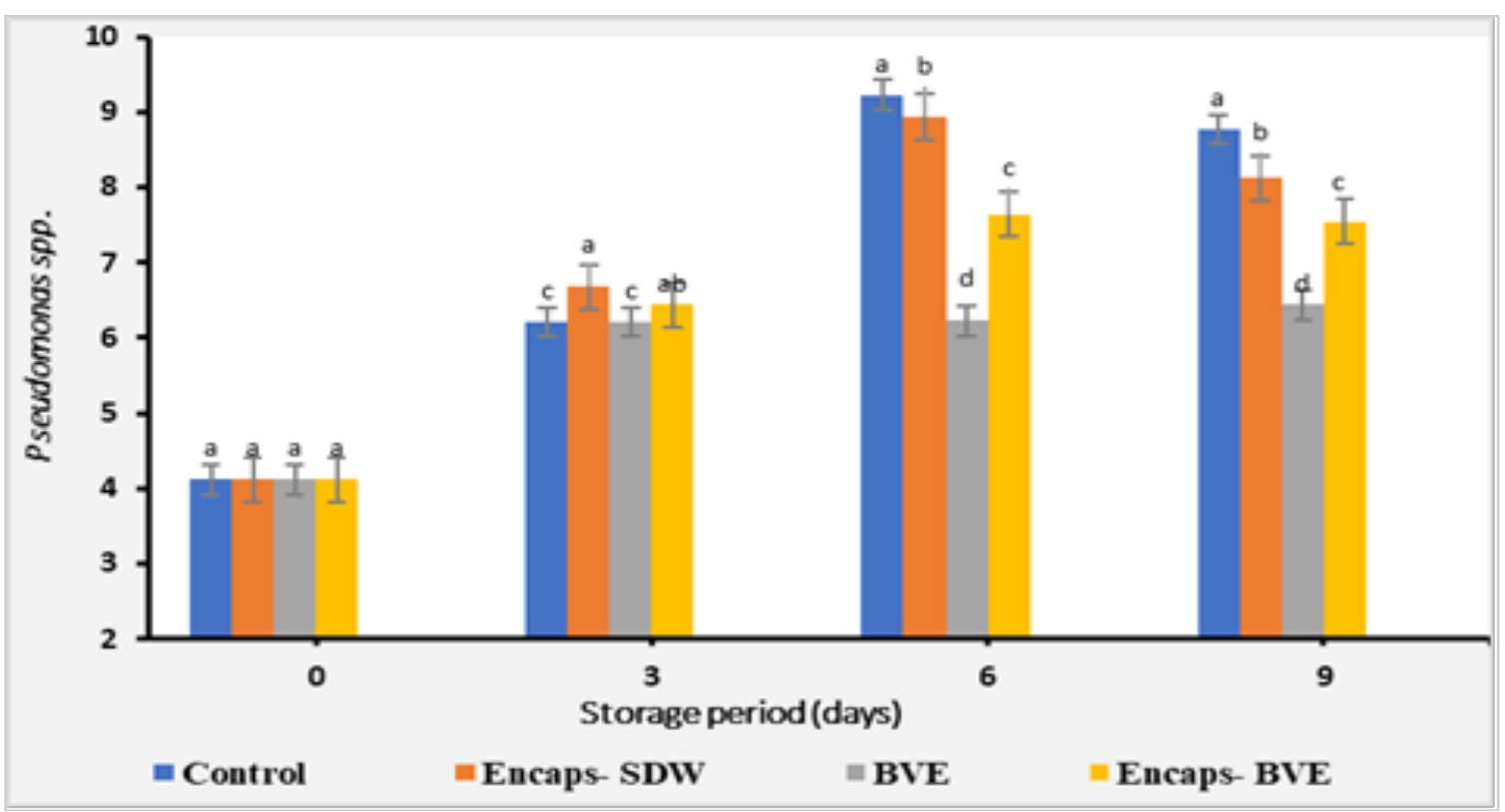

Figure 4. Growth of Pseudomonas spp. of beef burger patties incorporating Beta vulgaris L. root extract (BVE) or sterile distilled water (SDW) during 9 days of storage at $4 \pm 2{ }^{\circ} \mathrm{C}$

\subsection{Estimation of Color Characteristics}

The addition of BVE, including direct and encapsulated, significantly $(\mathrm{p}<0.05)$ affected the initial $L^{*}, a^{*}$, and $b^{*}$ characteristics of beef patties compared to the comparable controls of SDW and Encaps-SDW. While BVE was directly added to minced beef, $L^{*}$ revealed the significantly lowest value $(\mathrm{p}<0.05)$ of $41.21 \pm 0.23$, followed by Encaps-BVE and Encaps-SDW samples $(42.18 \pm 0.14$ and $46.25 \pm 0.11$, respectively). After six days of storage, the lightness levels of all different treatments increased (Fig. 5). After 9 days, they were $53.87 \pm 0.12,54.13 \pm 0.11,46.15 \pm 0.18$, and $46.01 \pm 0.17$, respectively, for Encaps-SDW, SDW, BVE, and Encaps-BVE. As illustrated in Figure 6, Encaps-BVE and BVE beef samples showed significantly higher $(\mathrm{p}<0.05) a^{*}$ values than Encaps-SDW and SDW samples control (13.57 \pm 0.12 and $13.45 \pm 0.11$, respectively). During 9 days of storage, Encaps-SDW and SDW control samples had $a^{*}$ values at $9.15 \pm 0.17$ and $7.99 \pm 0.14$, respectively, whereas Encaps-BVE and BVE samples had $a^{*}$ values of $15.33 \pm 0.12$ and $15.47 \pm 0.14$, respectively. Furthermore, the sample Encaps-BVE had the lowest $a^{*}$ value variations over the storage period. Compared to sample Encaps-BVE, sample BVE showed an unusual trend, declining $a^{*}$ value of nearly twice after 9 days. The $b^{*}$ values observed in Encaps-BVE and BVE beef samples were significantly affected $(\mathrm{p}<0.05)$, with initial levels of $15.24 \pm 0.13$ and $15.82 \pm 0.14$, respectively, when compared to Encaps-SDW and SDW samples, which had values of $13.34 \pm 0.24$ and $11.08 \pm 0.18$, respectively (Fig. 7). After 3 days of storage, the SDW and Encaps-SDW were significantly lower (7.32 \pm 0.15 and $7.99 \pm 0.12$, respectively); around the same time, samples of BVE and Encaps-BVE were less likely $(11.20 \pm 0.21$ and $10.54 \pm 0.09)$ to have a relationship with previously identified antimicrobial effect (Figures 5, 6, and 7). In comparison to BVE, Encaps-BVE had no significant impact $(p>0.05)$ on the beginning of colour parameters; when particularly in contrast to Encaps-SDW and SDW, samples BVE and Encaps-BVE had one of the most constant trends up to 9 days of storage. 


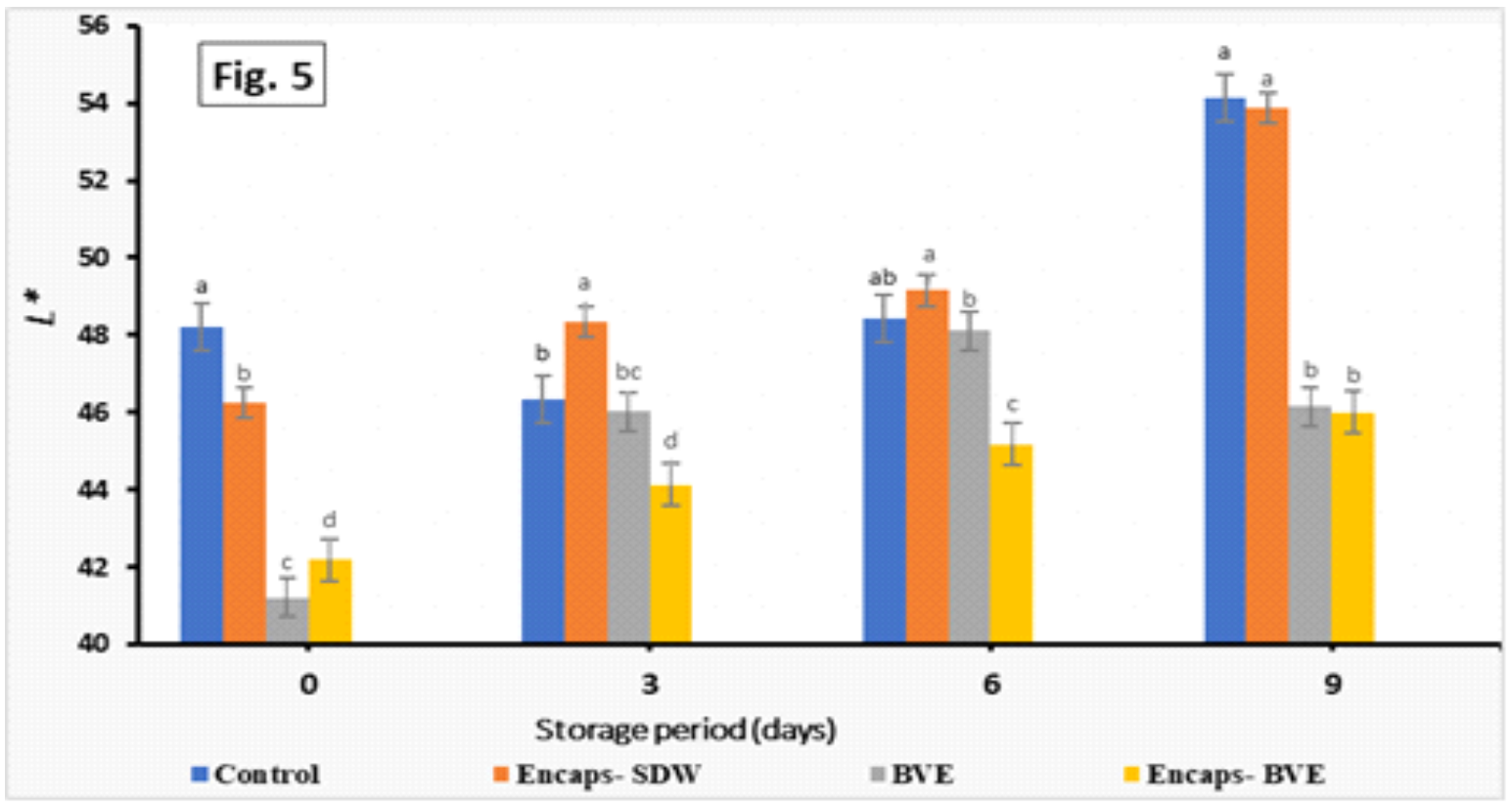

Figure 5. Color values $\mathrm{L}^{*}$ of burger patties incorporating Beta vulgaris root extract (BVE) and encapsulated Beta vulgaris l. root extract (Encaps-BVE). Sterile distilled water (SDW) or encapsulated sterile distilled water (Encaps-SDW) were used as controls. Color characteristics of burger surfaces were measured during 9 days of storage at $4 \pm 2^{\circ} \mathrm{C}$. The standard deviation $( \pm)$ of the mean is represented by vertical bars.

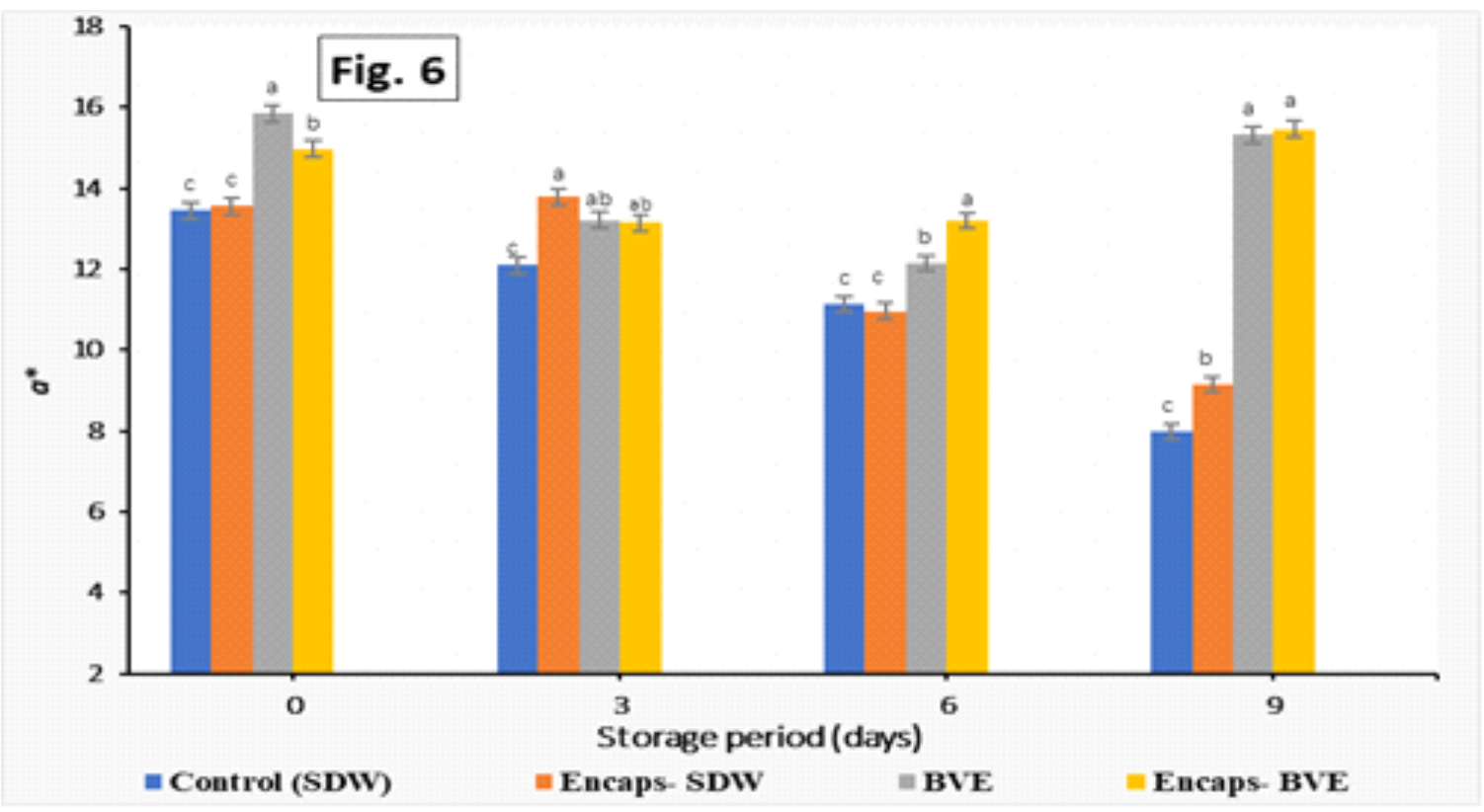

Figure 6. Color values a* of burger patties incorporating Beta vulgaris root extract (BVE) and encapsulated Beta vulgaris l. root extract (Encaps-BVE). Sterile distilled water (SDW) or encapsulated sterile distilled water (Encaps-SDW) were used as controls. Color characteristics of burger surfaces were measured during 9 days of storage at $4 \pm 2{ }^{\circ} \mathrm{C}$. The standard deviation $( \pm)$ of the mean is represented by vertical bars. 


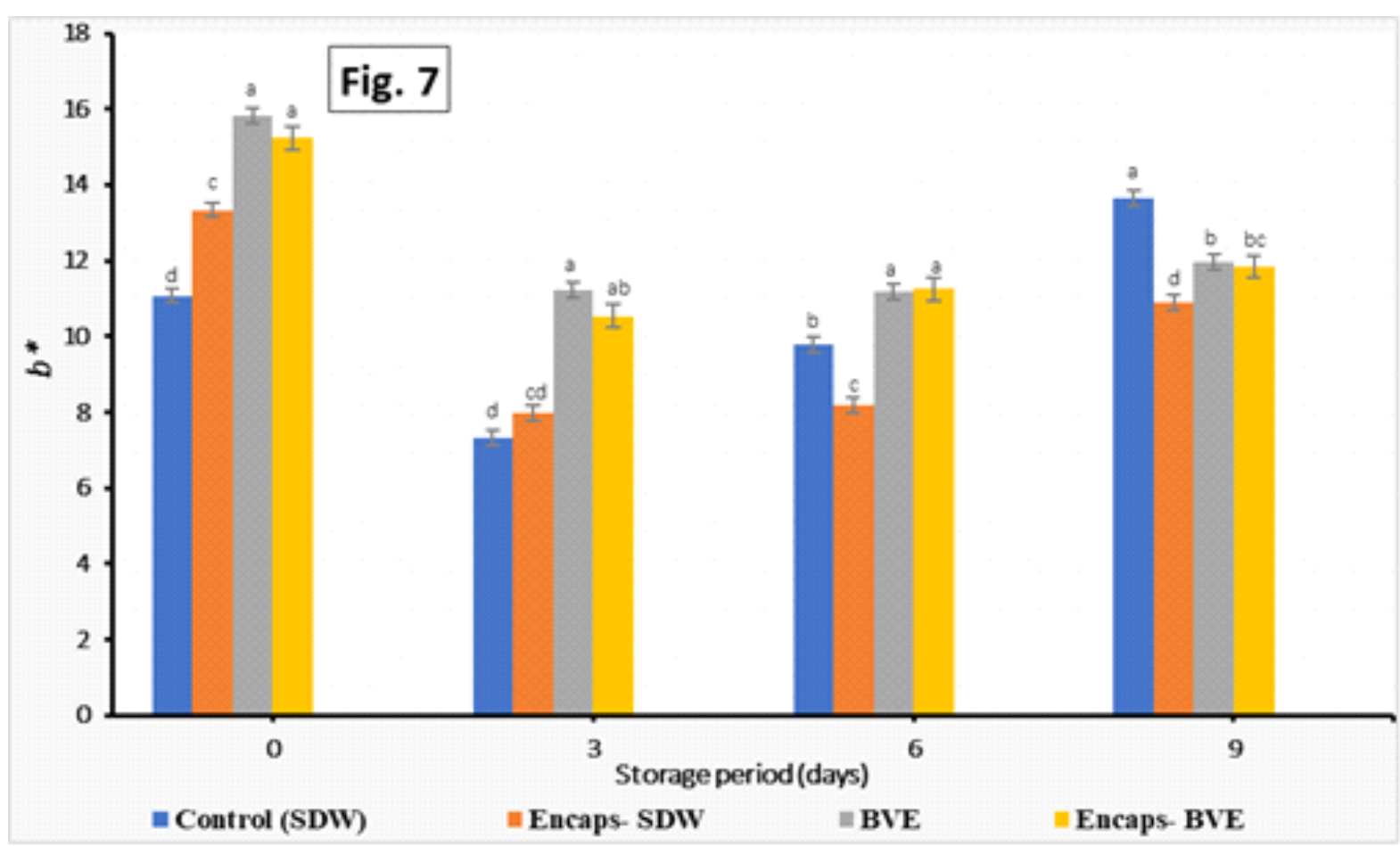

Figure 7. Color values $\mathrm{b}^{*}$ of burger patties incorporating Beta vulgaris root extract (BVE) and encapsulated Beta vulgaris l. root extract (Encaps-BVE). Sterile distilled water (SDW) or encapsulated sterile distilled water (Encaps-SDW) were used as controls. Color characteristics of burger surfaces were measured during 9 days of storage at $4 \pm 2^{\circ} \mathrm{C}$. The standard deviation $( \pm)$ of the mean is represented by vertical bars.

\subsection{Texture profile}

According to the storage period and considered parameters, the addition of BVE and Encaps-BVE considerably altered the textural characteristics of beef patties during storage (springiness, hardness, and cohesiveness) shown in Table 8, 9, and 10. Shortly after treatment (time 0 ), it was hardness comparable amongst treatments $(\mathrm{p}>0.05)$. After three and six days of storage at $4 \pm 2{ }^{\circ} \mathrm{C}$, all except one of the samples, the SDW control samples, had increased hardness values. After nine days of storage (Fig. 8), samples of BVE extract had the highest levels $(\mathrm{p}<0.05)$, followed by Encaps-BVE extract; there was no significant difference $(p>0.05)$ between the Encaps-SDW and SDW samples, which had the lowest hardness values. This impact was less apparent in sample Encaps-BVE extract due to the encapsulation of BVE extract. In addition to SDW and Encaps- SDW samples, cohesiveness and springiness improved in BVE and EncapsBVE extract samples with storage period, achieving significantly affected $(\mathrm{p}<0.05)$ a higher value during 3, 6, and 9 days (Fig. 9 and $10)$. 


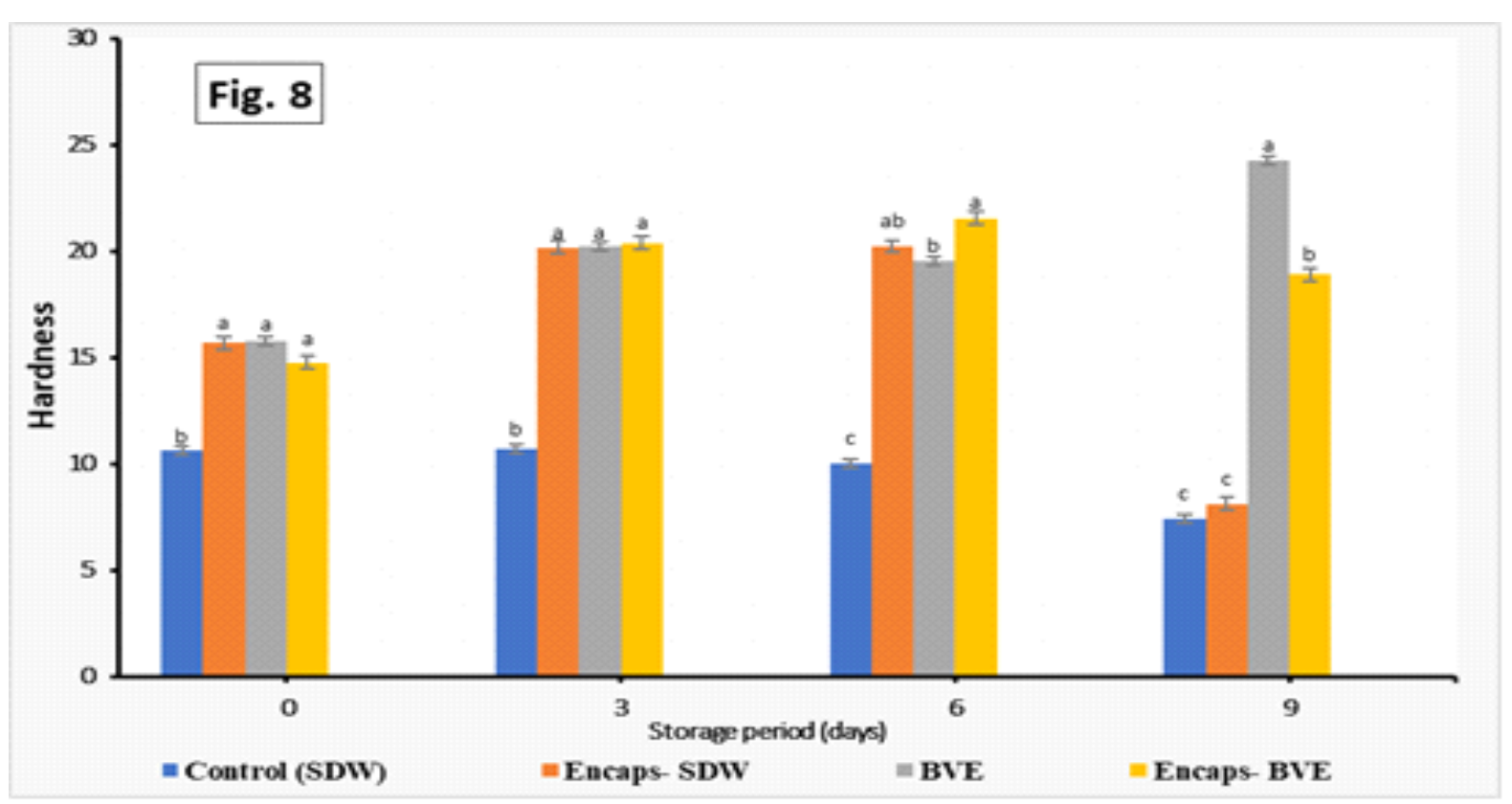

Figure 8. Hardness of beef burger patties incorporating Beta vulgaris $l$. root extract (BVE) or sterile distilled water (SDW) during 9 days of storage at $4 \pm 2{ }^{\circ} \mathrm{C}$.

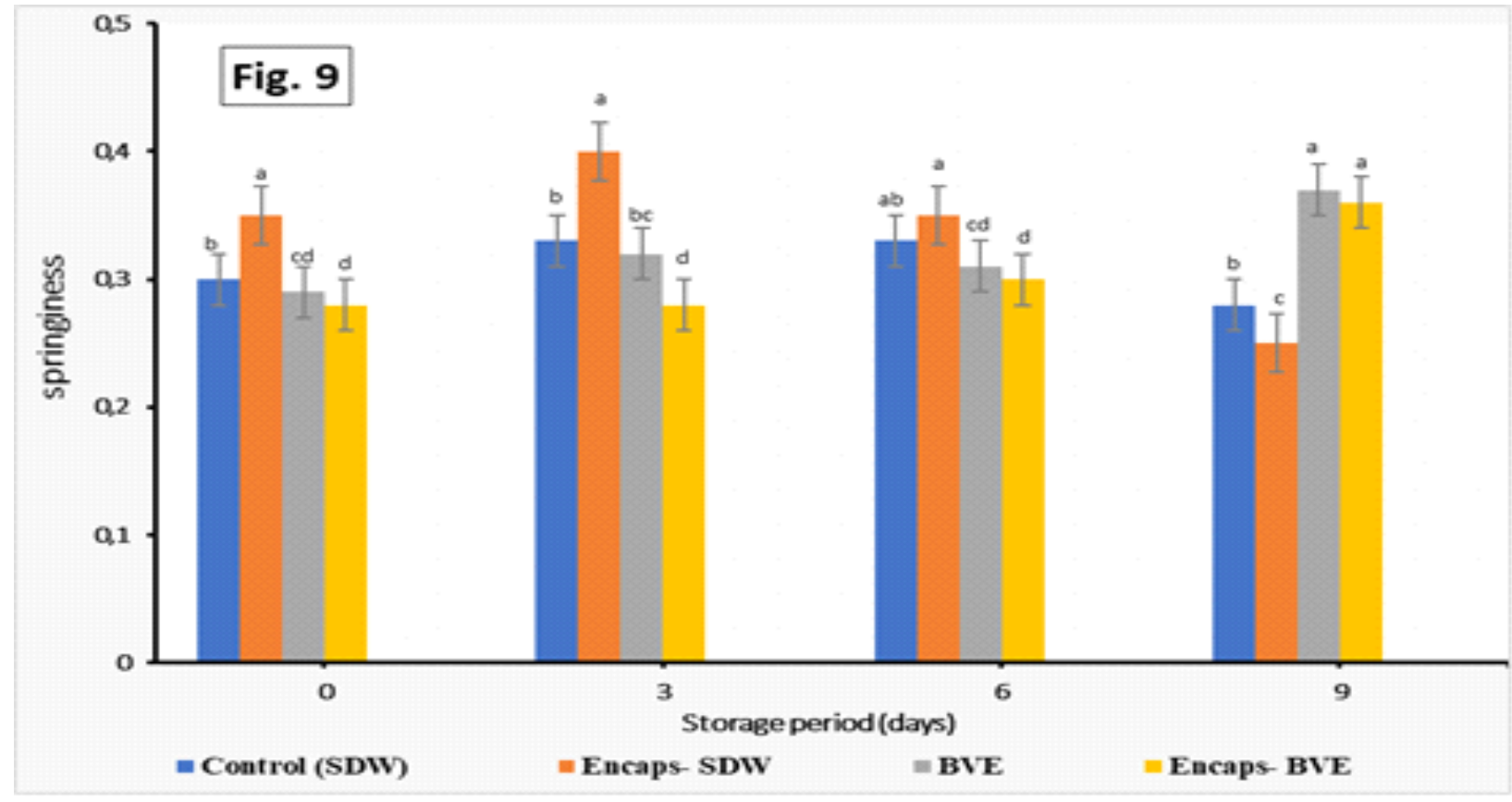

Figure 9. Springiness of beef burger patties incorporating Beta vulgaris $l$. root extract (BVE) or sterile distilled water (SDW) during 9 days of storage at $4 \pm 2{ }^{\circ} \mathrm{C}$. 


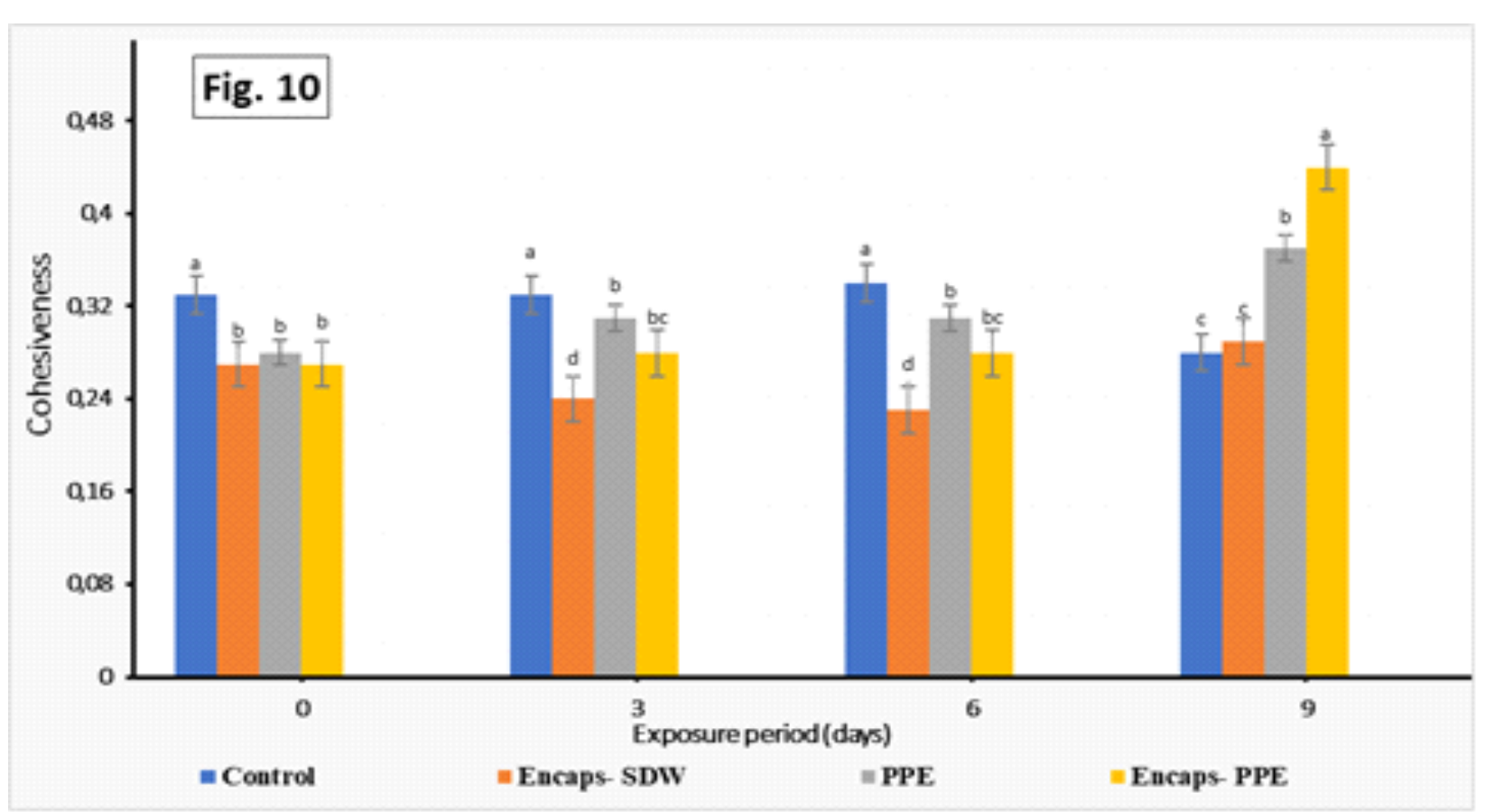

Figure 10. Cohesiveness of beef burger patties incorporating Beta vulgaris $l$. root extract (BVE) or sterile distilled water (SDW) during 9 days of storage at $4 \pm 2{ }^{\circ} \mathrm{C}$.

\subsection{Discussion}

The existence of bioactive compounds in red beetroot has influenced its pharmacological and physiological properties. Polyphenols, flavonoids, alkaloids, folic acid, tannins, ascorbic acid, and reducing sugars were identified as the primary ingredients of the red beetroot extract in earlier investigations (Azmir et al., 2013; Castro-Enríquez et al., 2020; Rashmi \& Negi, 2020). Flavonoids, for example, have been demonstrated to have antibacterial, antineoplastic, antiviral, antiallergic, and antioxidant, and antimicrobial properties (Sameeh et al., 2016; Karak, 2019; López-Lázaro, 2009;), acting as scavenging free radicals and metal chelators. Alkaloids have biological activities used in food industries, recreational drugs, and medicinal (Gülçin, 2011; El-Beltagi et al., 2018; Akanni et al., 2019). Tannins have been shown to protect carbohydrates and proteins against microbial breakdown in meat products (Jakobek, 2015; Bunglavan \& Dutta, 2013; Allam \& Dolgonova, 2017 ).

Furthermore, carotenoids protect against cancer, inflammatory processes, cardiovascular disease, and age-related dystrophy muscular
(Ahmed et al., 2014) and act as an antibacterial and antioxidant (Allam \& Dolgonova, 2017 El-Beltagi et al., 2018; Kandil et al., 2020). Odoh and Okoro (2012) observed that beetroot contains considerable amounts of vitamins, particularly Vit. C (4.36 mg/100 g), and their findings are identical to ours. Red beetroot has a high content of ascorbic acid, according to the investigation. This vitamin is essential for human food and nutrition, especially tissue maintenance and growth, neurotransmitter synthesis, hormone production, and immune responses. These findings are comparable to those of Vuli et. al., (2010) who found vanillic, ferulic, caffeic, $p$ hydroxybenzoic, and protocatechuic acids in beetroot. Pyo et. al., (2004) reported similar findings, identifying the following compounds: myricetin $(2.2 \mathrm{mg} / 100 \mathrm{~g} \mathrm{FW})$, catechin (6.7 $\mathrm{mg} / 100 \mathrm{~g} \mathrm{FW})$, quercetin $(7.5 \mathrm{mg} / 100 \mathrm{~g} \mathrm{FW})$, and kaempferol $(9.2 \mathrm{mg} / 100 \mathrm{~g} \mathrm{FW})$.

Quality characteristics and Microbiological activity, texture, and colour were examined in the storage process at refrigerated temperature (up to 9 days at $4 \pm 2{ }^{\circ} \mathrm{C}$ ) of beef burger pads made directly and encapsulated in alginate beads of BVE extract. Microbial results showed 
that both immediately added and or/not encapsulated BVE extract was conservative, which reduced significantly $(\mathrm{p}<0.05)$ Enterobacteriaceae, Pseudomonas ssp. counts and total mesophilic bacteria, compared to samples addicted with control samples SDW or SDW encapsulated. The commonly added BVE extract to burger formulations, on the other hand, appeared to be more capable of limiting the growth of approximated microbial populations of organisms, especially after 6 days; justifications for this must be attributed to the reality that almost all of the additional extracts interacted instantly with microorganisms and bacterial cells, decreasing their feasibility and effectiveness, or even with meat tissue and so limiting its degradation, resulting in the formation of smaller molecules that microorganisms can consume (Hassan et al., 2018). Parafati et al. (2019) previously published similar results on sliced beef, demonstrating the potential of BVE to decrease microbial activity while significantly at $4{ }^{\circ} \mathrm{C}$ of storage.

Furthermore, Kharrat et al. (2018) found that using BVE as a natural additive and preservative increases the microbial stability of salami, owing to the high content of betalains, phenolic, and flavonoids compounds in BVE extract. Various alternative strategies and preservation techniques were investigated because burgers are hazardous food from a microbiological or quality standpoint. Compared to control burger samples, Özvural et al. (2016) found that using encapsulated extract of green tea on burger pie preparation significantly decreased the coliform, total Mesophilic Bacteria, mold, and yeast count. According to observations from the last day of storage (6-8 days), the impacts of various preparations of chitosan and chitosan/sodium tripolyphosphate composite alternatives which include $\beta$ carotene as edible coatings and preservatives in hamburgers on bacteriological activity, oxidative, and quality characteristics, features were recently investigated by the same authors (Özvural et al., 2016; Özvural and Huang, 2018; Parafati et al., 2019; Hemmatkhah et al., 2020; Chaudhary et al.,
2020). The findings demonstrate that using the solution as a functional ingredient and edible coating was improved and much more successful microbiological characteristics and lipid oxidation. Chemical agents extracted from animals, plants, bacteria, and their metabolites that avoid the decomposition of different food items are natural preservatives. They work by inhibiting the growth of microbial, oxidation, and particular food enzymatic reactions. A preservative is a natural or synthetic derived chemical compound that protects finished products from decomposing due to microbial growth or other undesired chemical changes. They are applied to different foods to prevent them from spoiling, discoloration, or infection by microorganisms, and they improve their texture, colour, taste, and nutrition (Adham et al., 1998; Meyer et al., 2002; Kabak et al., 2006; Mei et al., 2019).

After storage, the $\mathrm{pH}$ of Encaps-SDW and SDW (control samples) increased (Biswas et al., 2004), most commonly due to the development of metabolites generated or primary microbial metabolites from protein beef deamination. The application of BVE extract had no discernible impact $(\mathrm{p}>0.05)$ on the $\mathrm{pH}$ of beef at the beginning of the storage period studied, so excluding that, it had observed effectiveness on microbial development. But even so, samples were treated with BVE extract (including both encapsulated and bulk) had the lowest of $\mathrm{pH}$ levels throughout the storage, implying an antibacterial activity of the bioactive extract components over time, a preventive role of meat tissue, and/or heterofermentative fungi and bacteria producing organic acids from BVE sugars (Sánchez et al., 2003; Del-Río et al., 2007; Hemmatkhah et al., 2020). When BVE and Encaps-BVE were compared, the latter had a relatively increased $\mathrm{pH}$ value because the extract was encapsulated in alginate beads. These findings agree with (Campolo et al., 2018; Parafati et al., 2019; Marrone et al., 2021;), who found that varying doses of BVE extract significantly impacted the $\mathrm{pH}$ of preserved beef treated with the extract. In terms of colour characteristics, control samples 
showed a considerable decrease in red colour ( $a^{*}$ parameter) during storage, most likely because of microbial degradation and the resulting rise in $\mathrm{pH}$, often associated with a shift in colour toward green. Meanwhile, the $a^{*}$ values of treated BVE extract samples, whether encapsulated or not, illustrated comparative stability and suggested that the extract has provided a preventive action against myoglobin oxidation, as previously characterized by Parafati et al. (2019). While there were nonsignificant changes $(\mathrm{p}>0.05)$ in $a^{*}$ values between samples containing encapsulated and non-encapsulated BVE, samples having encapsulated BVE showed a more consistent trend, except at four days. That according to (Campolo et al., 2018; Hemmatkhah et al., 2020). most packaged and raw minced beef samples demonstrated a significant decrease $(\mathrm{p}<0.05)$ in the $a^{*}$ parameter during the first day and throughout storage.

Additionally, the researchers also concluded that both $a^{*}$ and $b^{*}$ characteristics, owing to metmyoglobin synthesis, cause a decrease in the $b^{*}$ value. The Encaps-SDW and SDW samples demonstrate a more severe reduction in the $b^{*}$ values over storage, likely due to aerobic microorganisms consuming oxygen, resulting in lower oxymyoglobin contributing significantly to the yellow colour formation (Gülçin, 2011; Hemmatkhah et al., 2020). In this instance, the BVE extract encapsulated resulted in reduced $b^{*}$ parameter changes over the storage period, leading to colour preservation. The addition of BVE extract had a significant impact on hardness at the storage period (8 days), with the highest levels in samples treated or/not treated with BVE extract encapsulated, most certainly associated with the extract's carbohydrate content (Özvural et al., 2016; Parafati et al., 2019). Similarly, because once compared with untreated samples, springiness qualities in BVE and encapsulated BVE extracted samples increased significantly; the providing additional soluble proteins and carbohydrates in the extract may have improved the texture of meat products, resulting in structural resistance higher elasticity after the first component of beef product. Lastly, the cohesiveness characteristic demonstrated the most significant values of meat samples containing encapsulated extract, probably due to alginate's gelling characteristic.

\section{Conclusions}

One of the main aspects in enhancing quality, prolonging shelf-life, maintaining consumer protection, product safety, and minimizing waste was the microbial control in minced beef. This study follows a trend of identifying the various chemical compounds in red beetroot and evaluating their preventative role in extending food products' shelf life, including meat and its byproducts. Microbiological studies indicate that the addition of BVE and Encaps-BVE to burger preparation improved significantly $(\mathrm{P}<0.05)$ compared to control samples to total mesophilic bacteria, Pseudomonas spp. count, and Enterobacteriaceae. Moreover, results revealed that during the storage period, the addition of BVE kept beef minced almost constant in $\mathrm{pH}$ (average: 5.2-5.5), while control samples increased significantly $(\mathrm{p}<0.05)$ in $\mathrm{pH}$ values, possibly due to bacterial activity and degradation of protein caused by the production of amines, ammonia, and other essential substances.

Furthermore, after 9 days of the storage period, the sample containing Encaps-BVE demonstrated a steadier trend in terms of colour and texture characteristics than the other treatments. Confident that BVE is an effective technique of microorganisms' growth while storage, further research will be conducted to study the impact of beetroot extract, encapsulated or/not, on the cooked and grilled product's technological features as its sensory characteristics and acceptability. The research results have confirmed the feasibility of using BVE extract, whether encapsulated or/not in alginate beads. In contrast, a natural additive to meat product compositions maintains overall quality characteristics comparable to those of other extracts while also containing a significant inhibitor of antimicrobial agents, 
indicating that it could be used as a multifunctional value-added component.

\section{References}

Adham, N., Zgombick, J. M., Bard, J., \& Branchek, T. A. (1998). Functional characterization of the recombinant human 5-hydroxytryptamine7 (a) receptor isoform coupled to adenylate cyclase stimulation. Journal of Pharmacology and Experimental Therapeutics, 287(2), 508-514.

Aguirre, C. T., \& Santagapita, P. (2016). Physicochemical characterization of alginate beads containing sugars and biopolymers. Journal of quality and reliability engineering, (2016)1-8.

Ahmed, F., Fanning, K., Netzel, M., Turner, W., Li, Y., \& Schenk, P. M. (2014). Profiling of carotenoids and antioxidant capacity of microalgae from subtropical coastal and brackish waters. Food Chemistry, 165, 300-306.

Akanni, J. K., Oduola, L. I., Teslimah, G. O., \& Olufunmilayo, D. E. (2019). Socioeconomic Value, Chemical Composition, Biological Activities and Nutritional Value of Noni. American Journal of Biological Chemistry, 7(2), 38-46.

Albalá-Hurtado, S., Veciana-Nogués, M. T., Izquierdo-Pulido, M., \& Vidal-Carou, M. C. (1997). Determination of free and total furfural compounds in infant milk formulas by high-performance liquid chromatography. Journal of Agricultural and Food Chemistry, 45(6), 2128-2133.

Allam, A. Y, \& Dolgonova N. V. (2017) ${ }^{\text {a. }}$ Effect of the addition of chitosan prepared from green shrimp (Penaeus semisulcatus) on the sensory characteristics of cupcakes. Carpathian Journal of Food Science \& Technology, 9(1), 117-125.

Allam, A. Y, \& Dolgonova N. V. (2017) b. Effects of chitosan coating on postharvest quality of tomato fruits (Lycopersicon esculentum). Journal Ciencia e Tecnica Vitivinicola, 32(6), 295-271.

Aminzare, M., Aliakbarlu, J., \& Tajik, H. (2015). The effect of Cinnamomum zeylanicum essential oil on chemical characteristics of Lyoner-type sausage during refrigerated storage. J. Veterinary Research Forum, 6(1): 31-39.

Aneja, K. R., Dhiman, R., Aggarwal, N. K., \& Aneja, A. (2014). Emerging preservation techniques for controlling spoilage and pathogenic microorganisms in fruit juices. International journal of microbiology, (2014), 1-14.

Azmir, J., Zaidul, I. S. M., Rahman, M. M., Sharif, K. M., Mohamed, A. A., Sahena, F., Jahurul, M. H. A., Ghafoor K., Norulaini, N. A. N., Omar, A. K. M. (2013). Techniques for extraction of bioactive compounds from plant materials: A review. Journal of food engineering, 117(4), 426436.

Biswas, A. K. (2004). Integrated water resources management: a reassessment: a water forum contribution. Water international, 29(2), 248-256.

Bourne, E. (1978). The state of research on ego identity: A review and appraisal. Journal of youth and adolescence, 7(3), 223-251.

Bunglavan, S., \& Dutta, N. (2013). Use of tannins as organic protectants of proteins in digestion of ruminants. J. Livest. Sci, 4(1), 67-77.

Campolo, O., Giunti, G., Russo, A., Palmeri, V., \& Zappalà, L. (2018). Essential oils in stored product insect pest control. Journal of Food Quality, (2018), 1-12.

Castro-Enríquez, D., Montaño-Leyva, B., Del Toro-Sánchez, C., Juaréz-Onofre, J., Carvajal-Millan, E., Burruel-Ibarra, TapiaHernández, J. A., Barreras-Urbina C. G., \& Rodríguez-Félix, F. (2020). Stabilization of betalains by encapsulation - a review. Journal of food science and technology, 57(5), 1587-1600.

Celli, G. B., \& Brooks, M. S.-L. (2017). Impact of extraction and processing conditions on betalains and comparison of properties with anthocyanins - A current review. Food Research International, 100, 501-509.

Chaudhary, S., Kumar, S., Kumar, V., \& Sharma, R. (2020). Chitosan nanoemulsions are advanced edible coatings for fruits and vegetables: Composition, fabrication, and 
developments in the last decade. International journal of biological macromolecules, 152, 154-170.

Chouhan, S., Sharma, K., \& Guleria, S. (2017). Antimicrobial activity of some essential oils - present status and future perspectives. Medicines, 4(3), 58.

De-Ancos, B., Colina-Coca, C., GonzálezPeña, D., \& Sánchez-Moreno, C. (2015). Bioactive compounds from vegetable and fruit by-products. Biotechnol. Bioact. Compd. Sources Appl, 1-36.

Del-Río, E., Panizo-Morán, M., Prieto, M., Alonso-Calleja, C., \& Capita, R. (2007). Effect of various chemical decontamination treatments on natural microflora and sensory characteristics of poultry. International journal of food microbiology, 115(3), 268-280.

El-Beltagi, H. S., Mohamed, H. I., Megahed, B. M., Gamal, M., \& Safwat, G. (2018). Evaluation of some chemical constituents, antioxidant, antibacterial, and anticancer activities of Beta vulgaris L. root. Fresenius Environmental Bulletin, 27(9), 6369-6378.

Flores, M., \& Toldrá, F. (2020). Chemistry, safety, and regulatory considerations in the use of nitrite and nitrate from a natural origin in meat products. Meat Science, (171), 108272.

Fortunati, E., Mazzaglia, A., \& Balestra, G. M. (2019). Sustainable control strategies for plant protection and food packaging sectors by natural substances and novel nanotechnological approaches. Journal of the Science of Food and Agriculture, 99(3), 986-1000.

Gliszczynska, S., \& Anna, O. J. (2013). Antioxidant and Prooxidant Activity of Food Components. Food Oxidants and Antioxidants: Chemical, Biological, and Functional Properties, 375.

Goldman, I., \& Navazio, J. (2003). History and breeding of table beet in the United States. Plant Breeding Reviews, 22, 357-388.

Goupy, P., Hugues, M., Boivin, P., \& Amiot, M. J. (1999). Antioxidant composition and activity of barley (Hordeum vulgare) and malt extracts and of isolated phenolic compounds. Journal of the Science of Food and Agriculture, 79(12), 1625-1634.

Gülçin, İ. (2011). Antioxidant activity of eugenol: A structure-activity relationship study. Journal of medicinal food, 14(9), 975-985.

Hassan, Y. I., Lahaye, L., Gong, M. M., Peng, J., Gong, J., Liu, S., Yang, C. (2018). Innovative drugs, chemicals, and enzymes within the animal production chain. Veterinary research, 49(1), 1-17.

Hemmatkhah, F., Zeynali, F., \& Almasi, H. (2020). Encapsulated cumin seed essential oil-loaded active papers: Characterization and evaluation of the effect on quality attributes of beef hamburger. Food and bioprocess technology, 13(3), 533-547.

Jain, C., Khatana, S., \& Vijayvergia, R. (2019). Bioactivity of secondary metabolites of various plants: a review. International Journal of Pharmaceutical Sciences and Research, 10(2), 494-498.

Jakobek, L. (2015). Interactions of polyphenols with carbohydrates, lipids, and proteins. Food Chemistry, 175, 556-567.

Jeyanthi, R. L., Sharmila, S., Das, M. P., Seshiah, C. (2014). Extraction and purification of carotenoids from vegetables. J. Chem. Pharm. Res. 6(4), 594-598.

Kabak, B., Dobson, A. D., \& Var, I. 1. (2006). Strategies to prevent mycotoxin contamination of food and animal feed: a review. Critical reviews in food science and nutrition, 46(8), 593-619.

Kandil, A., Aly-Aldin, M., \& Allam, A. (2020). Quality Characteristics of Processed LowFat Beef Sausage as Affected by Chickpea Protein Isolates Prolonged Cold Storage. Journal of Food and Dairy Sciences, 11(12), 363-368.

Karak, P. (2019). Biological activities of flavonoids: an overview. International Journal of Pharmaceutical Sciences and Research, 10(4), 1567-1574.

Kharrat, A. B. J., Moutia, N., Khirouni, K., \& Boujelben, W. (2018). Investigation of electrical behavior and dielectric properties in polycrystalline $\operatorname{Pr}_{0.8} \mathrm{Sr}_{0.2} \mathrm{MnO}_{3}$ manganite 
perovskite. Materials Research Bulletin, 105, 75-83.

Kowalczewski, P., \& Andreani, L. C. (2015). Towards the efficiency limits of silicon solar cells: How thin is too thin? Solar Energy Materials and Solar Cells, 143, 260-268.

Kumar, S., \& Brooks, M. S.-L. (2018). Use of red beet (Beta vulgaris L.) for antimicrobial applications -a critical review. Food and bioprocess technology, 11(1), 17-42.

López-Lázaro, M. (2009). Distribution and biological activities of the flavonoid luteolin. Mini reviews in medicinal chemistry, 9(1), 31-59.

Mancinelli, E. (2008). e-Inclusion in the Information Society. Information Society From theory to political practice Coursebook, 171-182.

Mancinelli, L., \& Ozkan, A. (2006). Ownership structure and dividend policy: Evidence from Italian firms. European Journal of Finance, 12(03), 265-282.

Marrone, R., Smaldone, G., Ambrosio, R. L., Festa, R., Ceruso, M., Chianese, A., \& Anastasio, A. (2021). Effect of beetroot (Beta vulgaris) extracts on Black Angus burgers shelf life. Italian Journal of Food Safety, 10(1).

Mattila, K. J., Nieminen, M. S., Valtonen, V. V., Rasi, V. P., Kesäniemi, Y. A., Syrjälä, S. L., . . Jokinen, M. J. (1989). Association between dental health and acute myocardial infarction. British medical journal, 298(6676), 779-781.

Mei, J., Ma, X., \& Xie, J. (2019). Review on natural preservatives for extending fish shelf life. Foods, 8(10), 490.

Mercadante, A. Z., Capitani, C. D., Decker, E., \& Castro, I. A. (2010). Effect of natural pigments on the oxidative stability of sausages stored under refrigeration. Meat Science, 84(4), 718-726.

Meyer, A., Suhr, K., Nielsen, P., \& Holm, F. (2002). Natural food preservatives. Minimal processing technologies in the food industries, 8, 124-174.
Miguel, M. G. (2018). Betalains in some species of the Amaranthaceae family: A review. Antioxidants, 7(4), 53.

Muge, E. K., Karoney, E. M., Ochieno, D. M., Baraza, D. L., Nyaboga, E. N., \& Naluyange, V. (2020). Rhizobium improves nutritive suitability and tolerance of Phaseolus vulgaris to Colletotrichum lindemuthianum by boosting organic nitrogen content. Applied Soil Ecology, 149, 103534.

Neelwarne, B., \& Halagur, S. B. (2013). Red beet: an overview. Red Beet Biotechnology, $1-43$.

Ni, Z.-J., Wang, X., Shen, Y., Thakur, K., Han, J., Zhang, J. G., Hu, F., Wei, Z. J. (2021). Recent updates on the chemistry, bioactivities, mode of action, and industrial applications of plant essential oils. Trends in Food Science \& Technology, 110, 78-89.

Odoh, U., Ezugwu, C., \& Okoro, E. (2012). Quantitative phytochemical, proximate/nutritive composition analysis of Beta Vulgaris Linnaeus (Chenopodiaceae). Planta Medica, 78(11), PI116.

Ozsoy, N., Can, A., Yanardag, R., \& Akev, N. (2008). Antioxidant activity of Smilax excelsa L. leaf extracts. Food Chemistry, 110(3), 571-583.

Özvural, E. B., Huang, Q., \& Chikindas, M. L. (2016). The comparison of quality and microbiological characteristics of hamburger patties enriched with green tea extract using three techniques: Direct addition, edible coating, and encapsulation. LWT-Food Science and Technology, 68, 385-390.

Panchal, B. (2020). Regulation of flowering in vegetable crops under protected cultivation. Agriculture \& Food E-Newsletter, 2(11), $117-120$.

Parafati, L., Palmeri, R., Trippa, D., Restuccia, C., \& Fallico, B. (2019). Quality maintenance of beef burger patties by direct addiction or encapsulation of a prickly pear fruit extract. Frontiers in microbiology, 10, 1760.

Priyadarshani, I., \& Rath, B. (2012). Commercial and industrial applications of 
microalgae-A review. Journal of Algal Biomass Utilization, 3(4), 89-100.

Pyo, Y.-H., Lee, T.-C., Logendra, L., \& Rosen, R. T. (2004). Antioxidant activity and phenolic compounds of Swiss chard (Beta vulgaris subspecies cycla) extracts. Food Chemistry, 85(1), 19-26.

Rashmi, H. B., \& Negi, P. S. (2020). Phenolic acids from vegetables: A review on processing stability and health benefits. Food Research International, 136, 109298.

Ribeiro, J. S., \& Veloso, C. M. (2020). Microencapsulation of natural dyes with biopolymers for application in food: A review. Food Hydrocolloids, 106374.

Sakanaka, S., Tachibana, Y., \& Okada, Y. (2005). Preparation and antioxidant properties of extracts of Japanese persimmon leaf tea (kakinoha-cha). Food Chemistry, 89(4), 569-575.

Sameeh, M. Y., Mohamed, A. A., \& Elazzazy, A. M. (2016). Polyphenolic contents and antimicrobial activity of different extracts of Padina boryana Thivy and Enteromorpha sp. marine algae. Journal of Applied Pharmaceutical Science, 6(9), 8792.

Sánchez-Escalante, A., Djenane, D., Torrescano, G., Beltrán, J., \& Roncales, P. (2003). The antioxidant action of borage, rosemary, oregano, and ascorbic acid in beef patties packaged in a modified atmosphere. Journal of Food Science, 68(1), 339-344.

Saxena, A., Yadav, A. N., Rajawat, M., Kaushik, R., Kumar, R., Kumar, M., Shukla, L. (2016). Microbial diversity of extreme regions: an unseen heritage and wealth. Indian Journal of Plant Genetic Resources, 29(3), 246-248.

Tatli Seven, P., Seven, I., Karakus, S., Iflazoglu Mutlu, S., Arkali, G., Muge Sahin, Y., \& Kilislioglu, A. (2020). Turkish propolis and its nano form can ameliorate the side effects of cisplatin, which is a widely used drug in the treatment of cancer. Plants, 9(9), 1075.

Vuli, P., Badalament, M., \& Jaikamal, V. (2010). Maximizing test asset re-use across
MIL, SIL, and HIL development platforms, 287 (2) 508-514.

\section{Acknowledgment}

Egypt's Ministry of Higher Education is supporting this work. All authors express they're thanks to all staff members at Food Science and Technology Dept, Fac. of Agriculture, Menoufia University. 